\title{
BMJ Open Effect of social integration on the establishment of health records among elderly migrants in China: a nationwide cross-sectional study
}

\author{
Zhengyue Jing (D) , ${ }^{1}$ Yi Wang, ${ }^{1}$ Lulu Ding, ${ }^{1}$ Xue Tang, ${ }^{1}$ Yuejing Feng, ${ }^{1}$ \\ Chengchao Zhou (D) ${ }^{1,2}$
}

To cite: Jing Z, Wang Y, Ding L, et al. Effect of social integration on the establishment of health records among elderly migrants in China: a nationwide crosssectional study. BMJ Open 2019;9:e034255. doi:10.1136/ bmjopen-2019-034255

- Prepublication history and additional material for this paper are available online. To view these files, please visit the journal online (http://dx.doi org/10.1136/bmjopen-2019034255).

Received 14 September 2019 Revised 26 November 2019 Accepted 27 November 2019

Check for updates

(c) Author(s) (or their employer(s)) 2019. Re-use permitted under CC BY-NC. No commercial re-use. See rights and permissions. Published by BMJ.

${ }^{1}$ School of Public Health, Shandong University, Jinan, Shandong, China

${ }^{2} \mathrm{NHC}$ Key Laboratory of Health Economics and Policy Research, Shandong University, Jinan, China

Correspondence to

Professor Chengchao Zhou;

zhouchengchao@sdu.edu.cn

\section{ABSTRACT}

Objectives Essential public health service use among the migrants is the key obstacle of the equalisation of public health service in China. This study aims to investigate the status of the establishment of health records, and explore the effect of social integration on the establishment of health records among elderly migrants in China.

Design and setting This is a cross-sectional study of data from the 2015 National Internal Migrants Dynamic Monitoring Survey in China.

Participants and methods Respondents who not clear about whether they had established health records and who lived in the inflow area for less than 6 months were excluded. A total of 3158 migrants aged over 60 years were included in this study. Univariate logistic regression and multivariate logistic regression were employed to explore the association between social integration and establishment of health records.

Results Approximately $41.6 \%$ of elderly migrants established health records in their inflow communities. Those elderly migrants from higher-income households were less likely to establish health records $(p<0.001$; $\mathrm{OR}=0.64 ; 0.51-0.80)$. Elderly migrants with local medical insurance $(p<0.001 ; 0 R=2.03 ; 1.60-2.57)$, long-term settlement intention $(\mathrm{p}<0.001 ; 0 \mathrm{R}=1.37 ; 1.15-1.63)$, and had more than three local friends $(p<0.001 ; 0 R=1.54$; 1.27-1.86) were more likely to establish health records. Conclusions This study demonstrates a relationship between social integration and establishment of the health records among elderly migrants in China. Improving the social integration of elderly migrants might be helpful to enhance the equalisation of essential public health services.

\section{BACKGROUND}

Despite the tremendous development of the economy and society during the past decades in China, the development gap across regions has led to the emergence of large number of the migrant population. The number of migrant populations has been growing fast from 21.3 million in 1990 to 253 million in 2014. However, since 2015, the scale of migrant population has experienced a new
Strengths and limitations of this study

- The main strength of this study is that the use of multidimensional indicator social integration to explore the impact on the basic public health service utilisation among elderly migrants in China.

- This study only focuses on the establishment of archives for the elderly migrants, as most previous studies have neglected the migrant elderly.

- There were only a few indicators we used to measure social integration in this study.

- The cross-sectional data we used cannot predict the causal relationship.

change from a continuous rise to a slow decline, with a falling from 247 million in 2015 to 241 million in $2018 .^{1}$ Even so, from the Report on China's Migrant Population Development in 2018, we can know that the elderly migrant population size continuously increases rapidly, and the number of the elderly migrant population has risen from 5.03 million in 2000 to 13.04 million in 2015 . $^{2}$

Household registration system, namely, hukou in China, divided the residents status into urban and rural residency. ${ }^{3}$ Hukou determined residents' entitlement to public services and welfare benefits in that local place (such as housing, education and healthcare) ${ }^{4}$ It is very difficult to convert rural hukou into urban hukou for rural migrants. Some previous studies indicate that migrants are not entitled to the same social welfare and healthcare benefits as local residents with registered hukou. ${ }^{5-7}$

To reduce the potential gap, China first proposed the concept of the equalisation of basic public health services in 2009, which means each citizen has equal access to basic health public services regardless of gender, age, race, residence, occupation and income. ${ }^{8}$ Basic public health services 
are provided free of charge to all residents by disease prevention and control institutions, urban community healthcare centres, township hospitals and village clinics, mainly for disease prevention and control of residents. In 2013, China introduced relevant policies on equalisation of basic health public services for migrants, which covers 11 essential public health service items, including the establishment of health records. ${ }^{9}$ Health records are management tools that enable medical staff to store, access and manage their personal health information, so as to make decisions related to residents' health status. ${ }^{1011}$ The health records will also gradually realise computerised management, connection with the medical security system, interconnection of health management data and medical information, and ultimately realise the information sharing of cross-institutional and cross-regional medical service behaviours. ${ }^{12}$ Health records are not only an important information base for medical information share in China, but also a key item of the equalisation of basic public health services.

The primary beneficiaries of the health records are the elderly. ${ }^{10}$ The establishment of health records can help elderly migrants better understand their physical condition and improve the quality of life. ${ }^{13}$ However, the elderly migrants, as a special group, have the dual nature of the elderly and migrant, are more likely to encounter multiple problems. Previous studies found that the problems mainly focus on the health status, mental health, quality of life, social support, social integration, health service utilisation. ${ }^{14-19}$ Of these problems, social integration was not only one of the most important issues among the migrants, but also the root source of many other related problems. At present, there is no unified definition of social integration, but it can be clarified that social integration is multidimensional and has various definitions across disciplines. In this study, social integration means the adaption of the migrants to norm and values of the local 'main stream', ${ }^{20}$ which measured by economic status, social interaction/engagement and self-identify.

Previous studies have indicated that social integration has a protective effect on the health status of the elderly, ${ }^{21-23}$ but few studies have explored the effect of social integration on the essential public health service utilisation among migrants in China. In addition, some few studies in this topic explored the effect among the general population. Establishment of health records is even more vital for the elderly than the general population. However, to date, no studies have focused on the elderly migrants. This study aims to explore the effect of social integration on the establishment of health records among elderly migrants in China. To do so, we have the following specific objectives. First, we will investigate the status of the establishment of health records among elderly migrants. Second, we will examine the association between social integration and the establishment of health records among elderly migrants.

\section{METHODS}

\section{Data}

The data used for this study were from the 2015 National Internal Migrants Dynamic Monitoring Survey (NIMDMS), which was a large-scale nationally representative migrant sampling survey. The survey has been organised annually by National Health Commission of the People's Republic of China since 2009. The reason why we chose the 2015 is that only the 2015 NIMDMS contains information on health service utilisation and social integration of the elderly migrants.

The purpose of the NIMDMS is to understand the development status, public health service utilisation and family planning management of the migrants, etc. The survey was used a stratified three-stage probability proportionate to size to select participants. The respondents, namely, migrants, refer to those adults (15+) who did not have local hukou and had settled in local cities for more than 1 month. The respondents were interviewed face to face by interviewers who had received standard training. Written informed consents were obtained from all of the participants before they participated in this study.

\section{Data sample}

The 2015 NIMDMS questionnaire included four sections: (1) The basic information of family members and household/individual income and expenditure, including age, gender, marital status,mobility status, income and expenditure; (2)respondent's employment situation, including occupation and work type; (3) public health services and family planning services, including establishment of health records, medical insurance and basic information of respondent's own children and (4) health service utilisation of the elderly migrants.

We only adopted the questionnaires which were entirely answered by the respondents, a total of 4028 migrants aged over 60 years (observations) were eligible for inclusion criteria. Of whom, 281 respondents whose living time in inflow area were less than 6 months and 589 respondents whose response about whether they had established health records were not clear were excluded. Finally, 3158 elderly migrants were included in the analysis. Compared with the 3158 included participants, the average age of those excluded (589 respondents) was 66.1, with an SD of $5.6(\mathrm{p}=0.471)$. Most of the those excluded respondent migrants were male $(58.7 \%, \mathrm{p}=0.188)$, with the education level of junior school or below $(83.5 \%, \mathrm{p}=0.082)$, were intraprovincial migrants $(55.5 \%, \mathrm{p}=0.106)$, and the average time in inflow area is 7.0 years, with an SD of 6.1 years $(\mathrm{p}=0.533)$. There was no statistical difference in the main sociodemographic characteristics between the excluded participants and included participants (see online supplementary table 1 ).

\section{Measurement}

Dependent variables

The establishment of health records among elderly migrants are measured by the questions contained in the 
NIMDMS: 'Have you had established the health records in the inflow community'. If the response was 'no, I have never heard of this' or 'no, but I have heard of this', the establishment of health records was coded as 'no.' On the contrary, if the answer was 'I have established health records', the establishment of health records was coded as 'yes'.

\section{Social integration}

In this study, social integration is multidimensional and measured through three dimensions: economic integration, social interaction, self-identify, which was based on the measuring system presented by Yang ${ }^{24}$ and Zhou. ${ }^{25}$

Elderly migrant's economic integration was measured by three indicators: average monthly household income, occupation and local medical insurance. Of which the local medical insurance was measured by using a question of 'Whether you have local medical insurance in the inflow areas?' Household monthly income was divided into four categories according to the quartile method and quartile $1(\mathrm{Q} 1)$ was the lowest income and quartile $4(\mathrm{Q} 4)$ was the highest income. Social identify was measured by settlement willingness of elderly migrants, through a question of 'Whether you plan to settle in the inflow community for more than 5 years.' Social interaction was measured by the number of local friends of elderly migrant.

\section{Other variables}

Chronic disease was measured by the question of 'Have you been diagnosed with diabetes or hypertension?'.

\section{Data analysis}

IBM SPSS V.22.0 was used to conduct the statistical analysis. First, frequency and percentage were used to describe the elderly migrants' demographic characteristics. Second, $\chi^{2}$ tests were used to compare the establishment rate of health records across different subgroup of the elderly migrants. Third, univariate logistic regression and multivariate logistic regression were employed to explore the association between social integration and establishment of health records using OR and 95\% CIs. Sampling weights were used in all of the analyses to adjust for the survey design.

\section{Patient and public involvement}

All data in this study were derived from the 2015 NIMDMS database, no patients and the public were involved in the design or planning of this study.

\section{Ethical consideration}

This study was an analysis of a public access dataset of the 2015 NIMDMS. The survey was funded and organised by the National Population and Family Planning Commission of the People's Republic of China. All participants gave their informed written consent for participation prior to the face-to-face interview.

\section{RESULTS}

\section{Characteristics of the elderly migrants}

The characteristics of the participants were presented in table 1 . Of the 3158 elderly migrants, $41.6 \%$ established health records in the inflow communities. The average age of the elderly migrants is 66.1, with an SD of 5.4. Most of the elderly migrants were male $(61.6 \%)$, were rural origin $(56.8 \%)$, with the education level of junior school or below $(80.5 \%)$, married $(83.3 \%)$. As for the characteristics of migration, about $59.1 \%$ were intraprovincial migrants, and the average time in inflow area is 7.5 years, with an SD of 6.8 years. In the aspect of physical health, most of the elderly migrants had exercise less than $60 \mathrm{~min} /$ day $(66.7 \%$ ), about $19.0 \%$ had chronic disease.

\section{Social integration status of the elderly migrants}

Social integration was measured by economic integration, self-identify and social interaction (see table 2). With regard to the economic integration, $28.0 \%$ were in quartile $2(\mathrm{Q} 2)$. About $69.8 \%$ did not have a job and $89.0 \%$ did not have local medical insurance. In the aspect of the social identify, $72.1 \%$ of the elderly migrants decided to settle in their current residence in the future. As for the social interaction, $79.1 \%$ of the elderly migrants had more than three local friends.

\section{Relationship between social integration and the establishment of health records}

Univariate analyses showed that those elderly migrants who were urban origin $(\mathrm{p}=0.007)$, who were older $(\mathrm{p}=0.001)$, who had more years in the inflow areas $(\mathrm{p}=0.002)$, who had exercised over $60 \mathrm{~min} /$ day $(\mathrm{p}<0.001)$, who had local medical insurance $(p<0.001)$, who had decided to settle in current residence in the future 5 years $(p<0.001)$ and who had more than three local friends $(p<0.001)$ were more likely to establish health records. Those elderly migrants who were interprovincial migrants $(p<0.001)$, who were from higher-income households $(\mathrm{p}<0.001)$ and who had job in current residence $(\mathrm{p}=0.002)$ were less likely to establish the health records (see online supplementary table 2).

We used two multivariate models to estimate the effect of social integration on establishment of health records among elderly migrants. In table 3 , the model 1 only included social integration, which showed that the social integration, including dimensions of economic integration, social identity, social interaction, were statistically associated with the establishment of health records; the model 2 included the variables which was examined with statistical significance in the univariate logistic regressions in online supplementary table 2. After adjusting for the hukou, age, time in inflow area, movement area and exercise time per day, we found that social integration (economic integration, social identity, social interaction) were still associated with establishment of health records among elderly migrants. Specifically, those elderly migrants who were from higher-income households $(\mathrm{p}<0.001$, $\mathrm{OR}=0.64)$ were less likely to establish 
Table 1 Sociodemographic characteristics of the elderly migrants in China, 2015

\begin{tabular}{|c|c|c|c|}
\hline \multirow[b]{2}{*}{ Characteristics } & \multirow[b]{2}{*}{ Frequency (\%) } & \multicolumn{2}{|c|}{ Establishment of health records } \\
\hline & & Yes & No \\
\hline Observations & $3158(100.0)$ & $1313(41.6)$ & $1845(58.4)$ \\
\hline \multicolumn{4}{|l|}{ Sex } \\
\hline Male & $1946(61.6)$ & 783 (40.2) & $1163(59.8)$ \\
\hline Female & $1212(38.4)$ & $530(43.7)$ & $682(56.3)$ \\
\hline \multicolumn{4}{|l|}{ Educational attainment } \\
\hline Primary school or below & $1524(48.3)$ & $621(40.7)$ & $903(59.3)$ \\
\hline Junior school & 1017 (32.2) & $432(42.5)$ & $585(57.5)$ \\
\hline Senior school or above & 617 (19.5) & $260(42.1)$ & $357(57.9)$ \\
\hline \multicolumn{4}{|l|}{ Hukou } \\
\hline Rural & $1794(56.8)$ & 709 (39.5) & $1085(60.5)$ \\
\hline Urban & $1364(43.2)$ & 604 (44.3) & $760(55.7)$ \\
\hline \multicolumn{4}{|l|}{ Marital status } \\
\hline Single & $528(16.7)$ & $226(42.8)$ & $302(57.2)$ \\
\hline Married & $2630(83.3)$ & $1087(41.3)$ & $1543(58.7)$ \\
\hline Age (years) & $66.1 \pm 5.4$ & $66.5 \pm 5.6$ & $65.8 \pm 5.3$ \\
\hline \multicolumn{4}{|l|}{ Movement area } \\
\hline Intraprovincial & $1866(59.1)$ & $892(47.8)$ & $974(52.2)$ \\
\hline Interprovincial & $1292(40.9)$ & $421(32.6)$ & $871(67.4)$ \\
\hline Time in inflow area (years) & $7.5 \pm 6.8$ & $7.9 \pm 7.2$ & $7.2 \pm 6.5$ \\
\hline \multicolumn{4}{|l|}{ Daily exercise time (min) } \\
\hline $0-$ & $2106(66.7)$ & $826(39.2)$ & $1280(60.8)$ \\
\hline $60-$ & $1052(33.3)$ & $487(46.3)$ & $565(53.7)$ \\
\hline \multicolumn{4}{|l|}{ Chronic disease } \\
\hline No & $2558(81.0)$ & $1053(41.2)$ & $1505(58.8)$ \\
\hline Yes & $600(19.0)$ & $260(43.3)$ & $340(56.7)$ \\
\hline \multicolumn{4}{|l|}{ Self-reported health status } \\
\hline Health & 2904 (91.9) & $1200(41.3)$ & $1704(58.7)$ \\
\hline Unhealth & $254(8.1)$ & $113(44.5)$ & $141(55.5)$ \\
\hline
\end{tabular}

health records. Those elderly migrants who had local medical insurance $(p<0.001, O R=2.03)$, who decided to settle in current residence in the future 5 years $(p<0.001$, $\mathrm{OR}=1.37)$, who had more than three local friends $(\mathrm{p}<0.001, \mathrm{OR}=1.54)$ were more likely to establish health records. In addition, some other factors were also found to be associated with the establishment of health records among elderly migrant. Those who were interprovince migrants $(\mathrm{p}<0.001, \mathrm{OR}=0.57)$ were less likely to establish health records, and those who were older $(\mathrm{p}=0.048$, $\mathrm{OR}=1.01)$ and had exercised over $60 \mathrm{~min} /$ day $(\mathrm{p}=0.039$, $\mathrm{OR}=1.18$ ) were more likely to establish health records.

\section{DISCUSSION}

In this study, we found that approximately $41.6 \%$ of the migrant seniors $(60+)$ had established health records in the inflow communities. To establish the health records for migrants is the key to achieve the equalisation of public health service. The current study indicated that there was still a certain gap to the designated policy objective in the health records for the migrant seniors. Although most previous studies have explored the basic public health utilisation of the migrant population aged 15-59 years, they have neglected the establishment rate of health records of the migrant seniors $(60+) .{ }^{7627}$ We found that the establishment rate of health records of the migrant seniors $(60+)$ in this study was higher than the prevalence of $31.3 \%$ and $22.98 \%$ among the migrants aged $15-59$ years in 2013 and 2014, respectively. ${ }^{727}$ We speculated that possible reason is the seniors were the key groups in the implementation of health records compared with the migrant population aged 15-59.

This study found an association between social integration and establishment of health records in the inflow areas among migrant seniors. Such association was multifaceted, lying in the dimensions of economic integration, 
Table 2 Social integration of elderly migrants in China, 2015

\begin{tabular}{|c|c|c|c|c|}
\hline \multirow[b]{2}{*}{ Characteristics } & \multirow[b]{2}{*}{ Frequency (\%) } & \multicolumn{2}{|c|}{ Establishment of health records } & \multirow[t]{2}{*}{$P$ value } \\
\hline & & Yes & No & \\
\hline \multicolumn{5}{|c|}{ Economy integration } \\
\hline \multicolumn{4}{|c|}{ Monthly average household income* } & 0.000 \\
\hline Q1 & $833(26.4)$ & $376(45.1)$ & $457(54.9)$ & \\
\hline Q2 & $985(28.0)$ & $374(42.3)$ & $511(57.7)$ & \\
\hline Q3 & $773(24.5)$ & $345(44.6)$ & $428(55.4)$ & \\
\hline Q4 & $667(21.1)$ & $218(32.7)$ & $449(67.3)$ & \\
\hline Occupation & & & & 0.002 \\
\hline Unemployed & $2203(69.8)$ & $956(43.4)$ & $1247(56.6)$ & \\
\hline Employed & $955(30.2)$ & $357(37.4)$ & $598(62.6)$ & \\
\hline Local medical ins & & & & 0.000 \\
\hline No & $2809(89.0)$ & $1106(39.4)$ & $1703(60.6)$ & \\
\hline Yes & $349(11.0)$ & $207(59.3)$ & $143(40.7)$ & \\
\hline \multicolumn{5}{|l|}{ Self-identity } \\
\hline Settlement willins & & & & 0.000 \\
\hline No/not decide & $881(27.9)$ & $292(33.1)$ & $589(66.9)$ & \\
\hline Yes & $2277(72.1)$ & $1021(44.8)$ & $1256(55.2)$ & \\
\hline \multicolumn{5}{|l|}{ Social interaction } \\
\hline Number of local & & & & 0.000 \\
\hline $0-$ & $659(20.9)$ & $210(31.9)$ & $449(68.1)$ & \\
\hline $3-$ & $2499(79.1)$ & $1103(44.1)$ & $1396(55.9)$ & \\
\hline
\end{tabular}

The $p$ values in boldface mean statistical significance.

*Quartile 1 (Q1) is the poorest and quartile 4 (Q4) is the richest.

identification and social interaction. This finding would give impetus to improve the social integration so as to enhance the establishment rate of health records for the migrant seniors in the inflow areas.

Economic integration is associated with the establishment of health records among elderly migrants. We found that elderly migrants with local medical insurance tended to establish health records. Medical insurance could not only improve people's equal access to health service, but also affect the social integration of migrants. ${ }^{28} 29 \mathrm{~A}$ study by Zhao et al found that the non-use rate of health services among migrants with local medical insurance was lower than that among migrants without local medical insurance. ${ }^{30}$ The participation in local medical insurance played a key role in the utilisation of health service for migrants. We also found that migrant seniors with higher household income were less likely to establish health records, which is similar to a previous study by Qian et al. ${ }^{10}$ Essential public health service is provided free of charge to local residents and also the migrants by the government. The government subsidies for the public health services have increased from $¥ 15$ per capita in 2009 to $¥ 55$ per capita in 2018. Therefore, we speculated that the effect of the household income on establishment of health records was minimal. Another possible reason might be that those migrant seniors with higher household income would prefer to use self-paid high-quality health services rather than to use health records service. ${ }^{31}$

Self-identity integration is an important influencing factor in the establishment of health records. The elderly migrants with intention for long-term settlement were found to be more likely to establish health records. The establishment of health records would give the communities a certain understanding of the health status of the migrants, so as to develop corresponding health management strategies. ${ }^{32}$ Some previous studies showed that migrants with long-term willingness to settle were more likely to be well educated and willing to participate in social activities. ${ }^{33}$ They were of higher possibility to have stable work. ${ }^{34-36}$ This thus, they have a strong sense of identity and belonging in the inflow areas. ${ }^{37}$ As a result, such elderly migrants tended to regard themselves as local residents, and were more willing to use the local health services, including health records.

The higher social interaction integration was associated with the establishment of health records among elderly migrants. The migrant seniors who had more than three local friends were of higher probability to establish health records. A previous study indicated that maintaining good relationship with friends was important for older adults and had a positive impact on their subject wellbeing. ${ }^{38}$ Other studies showed that the number of local 
Table 3 The relationship between social integration and establishment of health records among elderly migrants in China, 2015

\begin{tabular}{|c|c|c|c|c|c|c|}
\hline \multirow[b]{2}{*}{ Variables } & \multicolumn{3}{|c|}{ Model 1 (no covariates) } & \multicolumn{3}{|c|}{ Model 2 (covariates) } \\
\hline & $P$ value & OR & OR $95 \% \mathrm{Cl}$ & $P$ value & OR & OR $95 \% \mathrm{Cl}$ \\
\hline \multicolumn{7}{|l|}{ Economy integration } \\
\hline \multicolumn{7}{|c|}{ Monthly average household income* } \\
\hline Q1 & & 1.0 & & & 1.0 & \\
\hline Q2 & 0.265 & 0.89 & 0.74 to 1.09 & 0.247 & 0.89 & 0.73 to 1.09 \\
\hline Q3 & 0.809 & 0.97 & 0.79 to 1.19 & 0.756 & 0.97 & 0.78 to 1.19 \\
\hline Q4 & $<0.001$ & 0.59 & 0.48 to 0.74 & $<0.001$ & 0.64 & 0.51 to 0.80 \\
\hline \multicolumn{7}{|l|}{ Occupation } \\
\hline Unemployed & & 1.0 & & & 1.0 & \\
\hline Employed & 0.001 & 0.77 & 0.66 to 0.90 & 0.186 & 0.88 & 0.74 to 1.06 \\
\hline \multicolumn{7}{|l|}{ Local medical insurances } \\
\hline No & & 1.0 & & & 1.0 & \\
\hline Yes & $<0.001$ & 2.06 & 1.64 to 2.59 & $<0.001$ & 2.03 & 1.60 to 2.57 \\
\hline \multicolumn{7}{|l|}{ Social identity } \\
\hline \multicolumn{7}{|l|}{ Settlement willingness } \\
\hline No/not decide & & 1.0 & & & 1.0 & \\
\hline Yes & $<0.001$ & 1.46 & 1.23 to 1.72 & $<0.001$ & 1.37 & 1.15 to 1.63 \\
\hline \multicolumn{7}{|l|}{ Social interaction } \\
\hline \multicolumn{7}{|l|}{ Number of local friends } \\
\hline $0-$ & & 1.0 & & & 1.0 & \\
\hline $3-$ & $<0.001$ & 1.60 & 1.33 to 1.92 & $<0.001$ & 1.54 & 1.27 to 1.86 \\
\hline \multicolumn{7}{|l|}{ Hukou } \\
\hline Rural & & & & & 1.0 & \\
\hline Urban & & & & 0.089 & 1.16 & 0.98 to 1.37 \\
\hline Age (years) & & & & 0.048 & 1.01 & 1.00 to 1.03 \\
\hline \multicolumn{7}{|l|}{ Movement area } \\
\hline Intraprovincial & & & & & 1.0 & \\
\hline Interprovincial & & & & $<0.001$ & 0.57 & 0.49 to 0.66 \\
\hline Time in inflow area (years) & & & & 0.461 & 1.00 & 0.99 to 1.02 \\
\hline \multicolumn{7}{|l|}{ Daily exercise time (min) } \\
\hline $0-$ & & & & & 1.0 & \\
\hline $60-$ & & & & 0.039 & 1.18 & 1.01 to 1.38 \\
\hline
\end{tabular}

The $p$ values in boldface mean statistical significance.

${ }^{*}$ Quartile 1 (Q1) is the poorest and Quartile 4 (Q4) is the richest.

friends was positively correlated with health service use among elderly migrants. ${ }^{39}$ Local friends could provide social support for elderly migrants and help them to be informed of local useful health information. This might explain why elderly migrants with more local friends were more likely to establish health records.

This study also found that age, interprovincial migration and physical exercises were the predictors for establishment of health records. Interprovincial elderly migrants were less likely to establish health records. For those interprovincial migrants, the social and cultural atmosphere (such as language, customs and habits) between migrants' place of origin and their new residence was different, thus these migrants were less likely to establish health records. ${ }^{40}$ The focus crowd of basic health service were the elderly population, and medical staff will take the initiative to provide health records services for the very elderly population, thus the older elderly migrants were more likely to establishment health record. We speculated that elderly migrants who had exercised over $60 \mathrm{~min} /$ day may have a higher selfhealth care consciousness and a higher probability of using preventive healthcare services, including health records. 
There were some limitations of this study. First, the data we used were cross-sectional; thus, we cannot predict the causal relationship between social integration and establishment of the health record. Second, there were only a few indicators we used to measure social integration in this study, which would be remedied in the follow-up study.

\section{CONCLUSIONS}

The current study indicated that there was still a certain gap to the designated policy objective in the health records for the migrant seniors (60+). This study also found an association between social integration and establishment of health records among elderly migrants. Such association was multifaceted, lying in the dimensions of economic integration, identification and social interaction. The government should take measures to improve the social integration of elderly migrants, carry out the health education and health promotion in the community, organise activities to encourage positive interaction between migrants and the local population, so as to improve the establishment of the health records among the migrant seniors.

Acknowledgements We thank the officials of health agencies, all participants and staffs at the study sites for their cooperation.

Contributors $\mathrm{CZ}$ and ZJ conceived the idea. YW, LD, XT and YF participated in the statistical analysis and interpretation of the results. ZJ drafted the manuscript. CZ gave many valuable comments on the draft and also polished it. All authors read and approved the final manuscript.

Funding We are grateful for funding support from the National Science Foundation of China (71473152 and 71774104), the China Medical Board (16-257), and Cheeloo Youth Scholar Grant, and Shandong University (IFYT1810, 2012DX006).

Competing interests None declared.

Patient consent for publication Not required.

Ethics approval The Ethical Committee of Shandong University reviewed and approved the study protocol.

Provenance and peer review Not commissioned; externally peer reviewed. Data availability statement Data are available on reasonable request.

Open access This is an open access article distributed in accordance with the Creative Commons Attribution Non Commercial (CC BY-NC 4.0) license, which permits others to distribute, remix, adapt, build upon this work non-commercially, and license their derivative works on different terms, provided the original work is properly cited, appropriate credit is given, any changes made indicated, and the use is non-commercial. See: http://creativecommons.org/licenses/by-nc/4.0/.

\section{ORCID iDs}

Zhengyue Jing http://orcid.org/0000-0002-0803-3785

Chengchao Zhou http://orcid.org/0000-0002-9364-3579

\section{REFERENCES}

1 Xiao Z, Xu S, Liu J. The report on urban migrant population's social integration in China No.1. Social Science Academic Press, 2018.

2 NHFPC. Report on China's migrant population development in 2018. China Population Press, 2018.

3 Peng B-li, Zou G-yang, Chen W, et al. Association between health service utilisation of internal migrant children and parents' acculturation in Guangdong, China: a cross-sectional study. BMJ Open 2018;8:e18844.
4 Bosker M, Deichmann U, Roberts M. Hukou and highways: the impact of China's spatial development policies on urbanization and regional inequality. . The World Bank, 2015: 71. 99-109.

5 Hu X, Cook S, Salazar MA. Internal migration and health in China. The Lancet 2008;372:1717-9.

6 Wu X, Treiman DJ. The household registration system and social stratification in China: 1955-1996. Demography 2004;41:363-84.

7 Zhang J, Lin S, Liang D, et al. Public health services utilization and its determinants among internal migrants in China: evidence from a nationally representative survey. Int $J$ Environ Res Public Health 2017;14:1002.

8 Opinions of the state Council of the central Committee of the Chinese Communist Party on deepening the health care system reform, 2018. Available: http://www.gov.cn/jrzg/2009-04/06/content_ 1278721.htm [Accessed 23 Oct 2019].

9 Pilot work programme for the equalization of basic public services in health and family planning for the migrant population, 2013. Available: http://www.nhc.gov.cn/ldrks/s3577/201312/39f344bd0a4f 419ca66ef8b933eaa561.shtml [Accessed 23 Oct 2019].

10 Qian Y, Ge D, Zhang L, et al. Does Hukou origin affect establishment of health records in migrant inflow communities? A nation-wide empirical study in China. BMC Health Serv Res 2018;18.

11 Guo X, Huang L. The situation and influence factors of health records of floating Population--Based on the National dynamic monitoring data of floating population survey of Sichuan Province in 2014. Population and Development 2016;22:84-9.

12 National basic public health service project management platform. Standard of health records management services. Available: http:// www.nbphsp.org.cn/jbgw/jkda/ [Accessed 23 Oct 2019].

$13 \mathrm{Li}$ X. Integration and development: an analysis of the equalization of basic public services for migrant population Journal of East China University of Science \& Technology; 2014.

14 de Oca VM, García TR, Sáenz R, et al. The linkage of life course, migration, health, and aging: health in adults and elderly Mexican migrants. J Aging Health 2011;23:1116-40.

15 van der Wurff FB, Beekman ATF, Dijkshoorn $\mathrm{H}$, et al. Prevalence and risk-factors for depression in elderly Turkish and Moroccan migrants in the Netherlands. J Affect Disord 2004;83:33-41.

16 Mui AC. Depression among elderly Chinese immigrants: an exploratory study. Soc Work 1996;41:633-45.

17 Alizadehkhoei M, Khosbin S, Khavarpour F. Assessing quality of life, well being and depression among Iranian Ederly in Australia. Iranian Journal of Ageing 2010;4.

18 Ertel KA, Glymour MM, Berkman LF. Effects of social integration on preserving memory function in a nationally representative us elderly population. Am J Public Health 2008;98:1215-20.

19 Aroian KJ, Khatutsky G, Tran TV, et al. Health and social service utilization among elderly immigrants from the former Soviet Union. $J$ Nurs Scholarsh 2001;33:265-71.

20 Dalgard OS, Thapa SB, Immigration TSB. Immigration, social integration and mental health in Norway, with focus on gender differences. Clin Pract Epidemiol Ment Health 2007;3.

21 Berkman LF, Glass T, Brissette I, et al. From social integration to health: Durkheim in the new millennium. Soc Sci Med 2000;51:843-57.

22 Zunzunegui M-V, Alvarado BE, Del Ser T, et al. Social networks, social integration, and social engagement determine cognitive decline in community-dwelling Spanish older adults. J Gerontol B Psychol Sci Soc Sci 2003;58:S93-100.

23 Arcury TA, Grzywacz JG, Ip EH, et al. Social integration and diabetes management among rural older adults. J Aging Health 2012;24:899-922.

24 Yang J. Index of assimilation for rural-to-urban migrants: a further analysis of the conceptual framework of assimilation theory. Population and Economics 2010;02:64-70.

$25 \mathrm{Zhou} \mathrm{H}$. Measurement and theoretical perspectives of immigrant assimilation in China. China Population Today 2012;36:42.

26 Yang X. Difference in utilization of basic public health service between registered and migrant population and its related factors in China. China Public Health 2018;34:781-5.

27 Guo J, Wen H, Zhou Q. Status quo and determinants on basic public health services of floating population. Chinese Journal of Health Policy 2014;7:51-6.

28 Qin X, Pan J, Liu GG. Does participating in health insurance benefit the migrant workers in China? an empirical investigation. China Economic Review 2014;30:263-78.

29 Chen L, Wang J, Fan H. Medical insurance and social integration of floating population: evidence from commercial insurance. Insurance Studies 2018;02:42-52. 
30 Zhao X, Lang Y, Ma C. Self-Reported morbidity and service utilization among migrant population in Beijing. Capital Journal of Public Health 2015;9:108-11.

31 Li W, Shen Y, Wang F. Utilization of essential public health service and its influencing factors among urban elderly people: a multilevel model analysis. Chinese Journal of Public Health 2019;01:71-5.

32 Chen Y, Zhang Y. Analysis on the status quo, problems and countermeasures of the basic public health service for floating population. Diet Health 2017;4.

33 Zhu Y, Chen W. The settlement intention of China's floating population in the cities: recent changes and multifaceted individuallevel determinants. Popul Space Place 2010;16:253-67.

34 Cao G, Li M, Ma Y, et al. Self-employment and intention of permanent urban settlement: Evidence from a survey of migrants in China's four major urbanising areas. Urban Stud 2015;52:639-64.

$35 \mathrm{Hu} F, \mathrm{Xu} Z$, Chen Y. Circular migration, or permanent stay? Evidence from China's rural-urban migration. China Economic Review 2011;22:64-74.
36 Xie J, Luo G. Statistical analysis of the floating population's wishes of urban integration in the Citizenization Journal of Guangzhou University; 2015

37 Liu Y, Liu Y, Li Z. Settlement intention of new migrants in China's large cities: patterns and determinants. Scientia Geographica Sinica 2014;34:780-7.

38 Huxhold O, Miche M, Schüz B. Benefits of having friends in older ages: differential effects of informal social activities on well-being in middle-aged and older adults. J Gerontol B Psychol Sci Soc Sci 2014;69:366-75.

39 Du B, Cao G, Xu F. Analysis on health status and medical service utilization among the migrant elderly in China. Chinese Journal of Health Policy 2018;11.

40 Tang D, Wang F. Influencing factors of basic public health service utilization of the migrant elderly. Chinese Journal of Health Policy 2018;11:17-22. 